\title{
Row Orientation and Defoliation Effects on Grape Composition of Vitis vinifera L. Agiorgitiko in Nemea (Greece)
}

\author{
Evangelia Chorti ${ }^{1}$, Serafeim Theocharis ${ }^{2}$, Konstantinos Boulokostas ${ }^{2}$, Stamatina Kallithraka ${ }^{3}$, Yorgos Kotseridis ${ }^{3}$ and \\ Stefanos Koundouras ${ }^{2}$ \\ ${ }^{1}$ Gaia Wines, 20500 Koutsi - Nemea, Greece, E-mail: echorti@hotmail.com \\ ${ }^{2}$ Laboratory of Viticulture, School of Agriculture, Aristotle University of Thessaloniki, 54124 Thessaloniki, Greece, E- \\ mail: mpoulokk@agro.auth.gr, sertheo@agro.auth.gr, skoundou@agro.auth.gr \\ ${ }^{3}$ Laboratory of Enology, Department of Food Science \& Technology, Agricultural University of Athens, 75 Iera Odos, \\ 11855 Athens, Greece, stamatina@aua.gr; ykotseridis@aua.gr \\ *Corresponding author: S. Koundouras
}

\begin{abstract}
Vineyard row orientation and canopy side exert a significant role in determining grape microclimate. The latter can be further manipulated by selective defoliation in the bunch zone. The aim of this study was to investigate the combined effects of row orientation and basal leaf removal on grape ripening of Vitis vinifera L. cv. Agiorgitiko in Nemea, Southern Greece. The experiment was conducted in 2017, on two adjacent vineyard blocks planted in 1990 on a flat site with two row orientations, North-South and East-West. Both blocks were grafted onto 41B rootstock and trained on a double cordon vertical trellis with uniform vineyard operations. Defoliation treatments included full leaf removal in the bunch zone performed at berry set and a non defoliated control, replicated three times in both blocks. Grapes were sampled at three time points from veraison to harvest from all canopy sides (i.e. E and $\mathrm{W}$ on North-South oriented rows and $\mathrm{N}$ and $\mathrm{S}$ on East-West oriented rows) and defoliation treatments and were analyzed for yield components and berry chemical composition. In addition, approximately $5 \mathrm{~kg}$ of grapes were collected from all plots and processed according to a standard winemaking protocol. Total yield and berry mass were lowest in the W-exposed and in the defoliated grapes. Must sugar and acid content, as well as wine alcohol and acidity did not depend on either factor. Skin anthocyanins and phenolics generally increased with defoliation. Skin anthocyanins and total berry phenolics were highest for north-south oriented rows, in the grapes of the cooler canopy side (E). Wines made from grapes of the $\mathrm{E}$ and $\mathrm{W}$ canopy sides showed the highest wine color, phenolic richness and the lowest $\mathrm{pH}$. No interaction between row orientation and defoliation was detected for any of the measured parameters. According to the results, the E-facing grapes on the north-south oriented rows showed generally a superior grape and wine composition for Agiorgitiko variety, under the semiarid conditions of the Nemea area.
\end{abstract}

\section{Introduction}

Bunch zone defoliation is a very common viticultural practice applied to manipulate canopy microclimate. It modifies bunch light environment, inducing a positive effect on skin anthocyanins of grape berries [1]. It also promotes air circulation into the canopy, reducing humidity and subsequently the risks of fungal infection [2]. However, while in cool climates, increased bunch sunlight exposure is related to improved anthocyanin and phenolic profile [3], in warm to hot, semi-arid conditions, the increased berry temperature caused by the extended sunlight exposure may reduce flavonoid biosynthesis [4]. In fact, high berry temperature, caused by increased sunlight exposure, has been shown to inhibit color development [5].

Vineyard row orientation is an important factor determining canopy microclimate and thus grape berry composition. It has been suggested that photosynthetically active radiation (PAR) absorption by the grapevine canopy is higher in north-south and northeast-southwest than in east-west row orientations for latitudes between 30 and $50^{\circ} \mathrm{N}$ [6]. It has been also shown that east-west row orientations [7] can result in reduced growth, yield and total dry mass per vine compared to north-south and northeast-southwest orientations in Chardonnay grown in the Northern hemisphere, while juice total soluble solids and $\mathrm{pH}$ were not affected. However, little evidence exists on the effects 
of canopy side on the chemical composition of grapes. Therefore, the aim of this study was to investigate the combined effects of row orientation and basal leaf removal on grape ripening of Vitis vinifera L. cv. Agiorgitiko under the semiarid climate of Southern Greece.

\section{Materials and Methods}

The experiment was conducted in 2017 in a 27-year old vineyard in Nemea (Greece), in two adjacent vineyard blocks situated on a flat site planted with two row orientations, North-South (N-S) and East-West (EW). Both blocks were planted with Vitis vinifera L. cv. 'Agiorgitiko' grafted onto 41B rootstock and trained on a double cordon vertical trellis with uniform vineyard operations.

Defoliation was performed at berry set and included full leaf removal in the bunch zone and a non defoliated control, replicated three times in both blocks. Grapes were sampled at three time points from veraison to harvest from all defoliation treatments and canopy sides (i.e. $\mathrm{E}$ and $\mathrm{W}$ expositions on $\mathrm{N}-\mathrm{S}$ oriented rows and $\mathrm{N}$ and $\mathrm{S}$ expositions on $\mathrm{E}-\mathrm{W}$ oriented rows) and were analyzed for bunch and berry weight and berry chemical composition [8].

Approximately $5 \mathrm{~kg}$ of grapes were collected from all plots and processed according to a standard red winemaking protocol. The produced wines were analyzed for several classical analytical parameters [9] and total phenolic content by Folin-Ciocalteau method [10].

\section{Results and discussion}

\subsection{Yield components}

Defoliation did not affect total yield per vine and cluster weight at harvest (Table 1), but the defoliated vines produced denser clusters with smaller berries compared to non-defoliated ones.

Table 1. Defoliation (D) and Exposition (E) effects on vine production components at harvest (Y, yield per vine in $\mathrm{kg}$; $\mathrm{BW}$, berry weight in $\mathrm{g}$; $\mathrm{CW}$, cluster weight in $\mathrm{g}$; $\mathrm{CD}$, cluster density in berries per $\mathrm{cm}$ ). Statistically significant differences within a factor are indicated by different letters $(\mathrm{p} \leq 0.05)$. * represents significance of the defoliation $\times$ exposition $(\mathrm{D} \times \mathrm{E})$ interaction at $\mathrm{p} \leq 0.05 ; \mathrm{ns}$, not significant.

\begin{tabular}{|c|c|c|c|c|c|}
\hline & & Y & BW & CW & CD \\
\hline \multirow{3}{*}{ D } & $\begin{array}{c}\text { Non } \\
\text { defoliated }\end{array}$ & 2.42 & $1.80^{\mathrm{a}}$ & 201.0 & $7.72^{\mathrm{b}}$ \\
\cline { 2 - 6 } & Defoliated & 2.00 & $1.66^{\mathrm{b}}$ & 199.8 & $8.56^{\mathrm{a}}$ \\
\hline \multirow{4}{*}{$\mathrm{E}$} & $\mathrm{N}$ & $2.51^{\mathrm{a}}$ & 1.81 & $226.5^{\mathrm{a}}$ & $8.31^{\mathrm{ab}}$ \\
\cline { 2 - 6 } & $\mathrm{S}$ & $2.27^{\mathrm{a}}$ & 1.73 & $165.3^{\mathrm{b}}$ & $7.68^{\mathrm{b}}$ \\
\cline { 2 - 6 } & $\mathrm{E}$ & $2.54^{\mathrm{a}}$ & 1.74 & $227.8^{\mathrm{a}}$ & $8.88^{\mathrm{a}}$ \\
\cline { 2 - 6 } & $\mathrm{W}$ & $1.52^{\mathrm{b}}$ & 1.66 & $181.9^{\mathrm{b}}$ & $7.68^{\mathrm{b}}$ \\
\hline \multicolumn{2}{|c|}{$\mathrm{D} \times \mathrm{E}$} & $\mathrm{ns}$ & $\mathrm{ns}$ & $\mathrm{ns}$ & $*$ \\
\hline
\end{tabular}

Canopy side exposition exerted a significant impact on all yield components apart from berry mass. In particular, vines exposed W presented the lowest yield, and together with grapes of $\mathrm{S}$ exposition, presented the smaller berries and the lowest cluster density (Table 1). $\mathrm{W}$ and $\mathrm{S}$ canopy sides in the North hemisphere receive the highest heat loads and, although microclimate parameters were not measured, it can be suggested that increased cluster temperature under $\mathrm{W}$ and $\mathrm{S}$ expositions inhibited berry and bunch growth. There was no interaction between defoliation and exposition for the measured parameters, with the exception of cluster density (Table 1).

\subsection{Grape composition}

Neither defoliation nor canopy exposition affected juice analytical parameters at harvest [7] and no defoliation $\times$ exposition interaction was detected for the same parameters (Table 2).

Table 2. Defoliation (D) and Exposition (E) effects on must chemical composition at harvest (TSS, total soluble solids in ${ }^{\circ}$ Brix; TA, titratable acidity in $g$ of tartaric acid per L of juice); ns, not significant.

\begin{tabular}{|c|c|c|c|c|}
\hline & & TSS & TA & $\mathrm{pH}$ \\
\hline \multirow{3}{*}{$\mathrm{D}$} & Non defoliated & 21.1 & 6.5 & 3.43 \\
\cline { 2 - 5 } & Defoliated & 22.3 & 5.9 & 3.55 \\
\hline \multirow{3}{*}{$\mathrm{E}$} & $\mathrm{N}$ & 21.6 & 6.7 & 3.40 \\
\cline { 2 - 5 } & $\mathrm{S}$ & 21.1 & 6.7 & 3.39 \\
\cline { 2 - 5 } & $\mathrm{E}$ & 21.9 & 5.9 & 3.52 \\
\cline { 2 - 5 } & $\mathrm{W}$ & 21.5 & 5.9 & 3.62 \\
\hline \multicolumn{2}{|c|}{$\mathrm{D} \times \mathrm{E}$} & $\mathrm{ns}$ & $\mathrm{ns}$ & $\mathrm{ns}$ \\
\hline
\end{tabular}

Grape skins from the vines where defoliation was applied presented higher content (expressed per single berry) and concentration (expressed per berry weight) of total anthocyanins and total phenols (Table 3). High light incidence on grapes is generally considered to promote anthocyanin accumulation in the skins [1].

Table 3. Defoliation (D) and Exposition (E) effects on berry skin phenolic composition measured at harvest (TA/B, total anthocyanins in mg per berry; $\mathrm{TP} / \mathrm{B}$, total phenols in absorbance units $(\mathrm{au})$ per berry; TA/W, total anthocyanins in mg per $\mathrm{g}$ of berry; TP/W, total phenols in au per g of berry;). Statistically significant differences within a factor are indicated by different letters $(\mathrm{p} \leq 0.05)$; ns, not significant.

\begin{tabular}{|c|c|c|c|c|c|}
\hline & & TA/B & TP/B & TA/W & TP/W \\
\hline \multirow{2}{*}{$\mathrm{D}$} & $\begin{array}{c}\text { Non } \\
\text { defoliated }\end{array}$ & $1.46^{\mathrm{b}}$ & 3.11 & $0.85^{\mathrm{b}}$ & $1.79^{\mathrm{b}}$ \\
\cline { 2 - 6 } & Defoliated & $1.63^{\mathrm{a}}$ & 3.11 & $1.00^{\mathrm{a}}$ & $1.91^{\mathrm{a}}$ \\
\hline \multirow{3}{*}{$\mathrm{E}$} & $\mathrm{N}$ & $1.34^{\mathrm{c}}$ & $3.13^{\mathrm{ab}}$ & $0.77^{\mathrm{c}}$ & $1.78^{\mathrm{b}}$ \\
\cline { 2 - 6 } & $\mathrm{S}$ & $1.41^{\mathrm{bc}}$ & $2.83^{\mathrm{b}}$ & $0.86^{\mathrm{bc}}$ & $1.73^{\mathrm{b}}$ \\
\cline { 2 - 6 } & $\mathrm{E}$ & $1.81^{\mathrm{a}}$ & $3.40^{\mathrm{a}}$ & $1.08^{\mathrm{a}}$ & $2.02^{\mathrm{a}}$ \\
\cline { 2 - 6 } & $\mathrm{W}$ & $1.56^{\mathrm{b}}$ & $3.10^{\mathrm{ab}}$ & $0.93^{\mathrm{b}}$ & $1.85^{\mathrm{b}}$ \\
\hline \multicolumn{2}{|c|}{$\mathrm{D} \times \mathrm{E}$} & $\mathrm{ns}$ & $\mathrm{ns}$ & $\mathrm{ns}$ & $\mathrm{ns}$ \\
\hline
\end{tabular}

Exposition also affected phenolic accumulation in the skins, the most advantageous one for phenolic compound accumulation being the $\mathrm{E}$ side on $\mathrm{N}-\mathrm{S}$ oriented rows (Table 3), where the grapes were exposed to sunlight only during the cooler hours of the day. On the contrary, $\mathrm{N}$ exposed grapes had the lowest anthocyanin content, on 
average, possibly due to lower grape exposure to sunlight [1]. No interaction between defoliation and exposition was detected for skin polyphenolic parameters (Table 3).

A positive response of skin anthocyanin levels to light exposure on the coolest canopy side has been previously reported [4]. Another study [11] suggested that anthocyanin accumulation is usually higher in the berries on the bunch side facing outside the canopy rather than inside, with the exception of $\mathrm{W}$ exposed bunches, probably due to elevated temperature of the skins. It has also been suggested that the combined effect of solar radiation and elevated temperature on anthocyanin accumulation may be linked, among other factors, to genotype [12], allowing some cultivars to benefit from light exposure even at higher temperature levels.

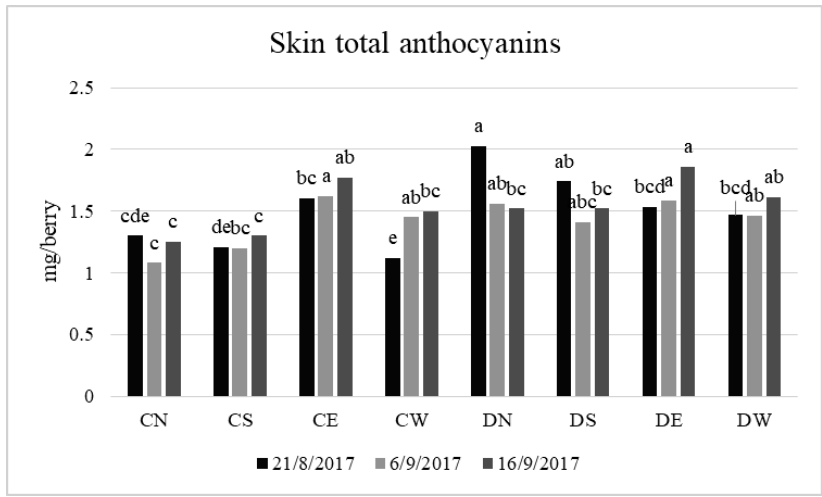

Figure 1. Skin anthocyanin accumulation in $\mathrm{mg} /$ berry during ripening $(\mathrm{CN}$, non-defoliated/ $\mathrm{N}$ exposition; $\mathrm{CS}$, nondefoliated/S exposition; CE, non-defoliated/E exposition; CW, non-defoliated/W exposition; DN, defoliated/N exposition; DS, defoliated/S exposition; DE, defoliated/E exposition; DW, defoliated/W exposition). Statistically significant differences within a factor are indicated by different letters $(\mathrm{p} \leq 0.05)$.

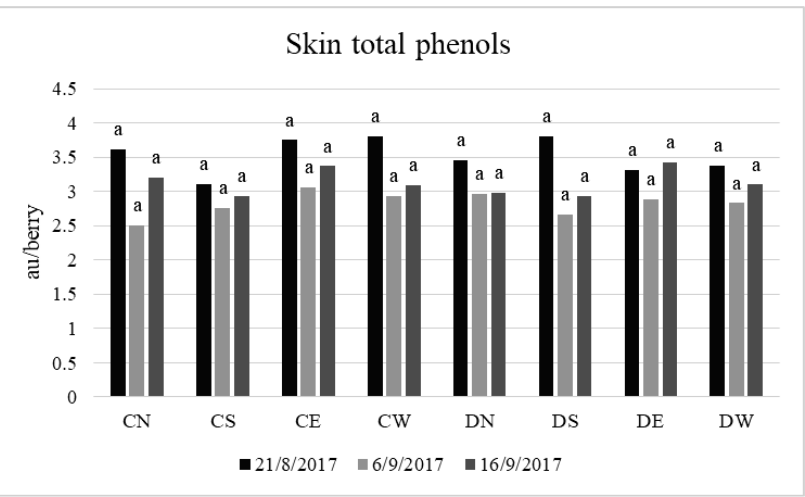

Figure 2. Skin total phenols evolution in au/berry during ripening $(\mathrm{CN}$, non-defoliated/ $\mathrm{N}$ exposition; $\mathrm{CS}$, nondefoliated/S exposition; CE, non-defoliated/E exposition; CW, non-defoliated/W exposition; DN, defoliated/N exposition; DS, defoliated/S exposition; DE, defoliated/E exposition; DW, defoliated/W exposition). Statistically significant differences within a factor are indicated by different letters $(\mathrm{p} \leq 0.05)$.
Considering individual treatments, the defoliated treatment with E exposition (DE) presented the highest values of anthocyanins in the skins at harvest (followed by $\mathrm{CE}$ and $\mathrm{DW}$ ) although the $\mathrm{N}$-exposed defoliated grapes had the highest content at the beginning of the ripening period (Fig. 1). The non-defoliated treatments with $\mathrm{N}$ and $\mathrm{S}$ exposition (CN and $\mathrm{CS}$ ) presented the lowest values at harvest. It is noteworthy that skin anthocyanins declined in most cases during harvest in the grapes of the $\mathrm{N}$ and $\mathrm{S}$-exposed canopy sides whereas they increased reaching maximum values at harvest for the $\mathrm{E}$ and $\mathrm{W}$-exposed sides. There were no differences in skin TP among the 8 treatments throughout ripening (Fig. 2).

\subsection{Wine composition}

Defoliation had no effect on wine alcohol content or titratable acidity (Table 4). S-exposed grapes produced the wines with the highest $\mathrm{pH}$ values, followed by vines exposed to $\mathrm{N}$ and $\mathrm{E}$ (Table 4). There was no interaction between defoliation and exposition, with the exception of wine $\mathrm{pH}$. According to previous works, direct light exposure of berries led to higher ratio of tartaric to malic acid in Syrah grapes [13].

Table 4. Defoliation (D) application and Exposition (E) effects on wine composition. (TA, titratable acidity in $g$ of tartaric acid per L of wine). Statistically significant differences within a factor are indicated by different letters $(p \leq 0.05)$. * represents significance of the defoliation $\times$ exposition $(\mathrm{D} \times \mathrm{E})$ interaction at $\mathrm{p} \leq 0.05$; ns, not significant.

\begin{tabular}{|c|c|c|c|c|}
\hline & & Alc. $\%$ & TA & $\mathrm{pH}$ \\
\hline \multirow[t]{2}{*}{$\mathrm{D}$} & $\begin{array}{c}\text { Non } \\
\text { defoliated }\end{array}$ & 12.91 & 6.27 & 3.77 \\
\hline & Defoliated & 13.31 & 6.37 & 3.75 \\
\hline \multirow{4}{*}{ E } & $\mathrm{N}$ & 13.33 & 6.45 & $3.80^{\mathrm{ab}}$ \\
\hline & $\mathrm{S}$ & 13.45 & 6.24 & $3.84^{\mathrm{a}}$ \\
\hline & $\mathrm{E}$ & 12.83 & 6.24 & $3.71^{b c}$ \\
\hline & W & 12.85 & 6.34 & $3.69^{\mathrm{c}}$ \\
\hline & $\mathrm{D} \times \mathrm{E}$ & ns & $\mathrm{ns}$ & $*$ \\
\hline
\end{tabular}

Table 5. Defoliation (D) and Exposition (E) effects on wine phenolic composition. (CI, color intensity, OD 280, total polyphenolic index; TP, total phenols in mg of gallic acid per L of wine). Statistically significant differences within a factor are indicated by different letters $(p \leq 0.05)$. ${ }^{*}$ represents significance of the defoliation $\times$ exposition $(\mathrm{D} \times \mathrm{E})$ interaction at $\mathrm{p} \leq 0.05 ; \mathrm{ns}$, not significant.

\begin{tabular}{|c|c|c|c|c|}
\hline & & CI & OD 280 & $\mathrm{TP}$ \\
\hline \multirow[t]{2}{*}{ D } & $\begin{array}{c}\text { Non } \\
\text { defoliated }\end{array}$ & 4.78 & $37.44^{\mathrm{b}}$ & 299.85 \\
\hline & Defoliated & 5.01 & $41.2^{\mathrm{a}}$ & 310.68 \\
\hline \multirow{4}{*}{ E } & $\mathrm{N}$ & $4.33^{c}$ & 37.3 & $286.03^{b}$ \\
\hline & S & $4.62^{\mathrm{bc}}$ & 37.81 & $289.84^{b}$ \\
\hline & $E$ & $5.22^{\mathrm{ab}}$ & 40.96 & $309.24^{\mathrm{ab}}$ \\
\hline & $\mathrm{W}$ & $5.40^{\mathrm{a}}$ & 41.21 & $335.96^{\mathrm{a}}$ \\
\hline \multicolumn{2}{|c|}{$\mathrm{D} \times \mathrm{E}$} & ns & ns & ns \\
\hline
\end{tabular}


Wines produced from defoliated vines presented higher values of total polyphenolic index, but there was no difference in the concentration of total phenols (Table $5)$. Wines made from $\mathrm{W}$-exposed grapes presented higher color (CI) and phenolic content (TP) values, followed by those from E exposition.

\section{Conclusions}

In warm, semiarid vine growing regions, achieving phenolic maturity when berry sugar content and acidity are at optimum levels can sometimes be an impossible task. As a result, growers either have to wait for phenolic maturity at the cost of producing wines with high alcohol content and unbalanced acidity, or harvest at technological maturity, risking to produce wines with poor color and unripe, astringent tannins.

Bunch zone defoliation at berry set promoted anthocyanin and phenolic accumulation in skins without advancing berry ripeness. As a result, the wines produced from grapes that had undergone defoliation presented a more intense color and higher total polyphenolic index compared to the non-defoliated ones, without presenting any signs of advanced or over ripeness: wine alcohol content and acidity were similar to those produced from the non-defoliated vines.

Regarding canopy side effect, E side exposition on N$\mathrm{S}$ oriented rows was proved as the most beneficial for berry anthocyanin and phenolic compound biosynthesis. It is also very important that $\mathrm{E}$ exposition promoted phenolic maturity without advancing pulp maturity, as it had no effect on juice sugar content, acidity and $\mathrm{pH}$. However, maximum wine color and lowest wine $\mathrm{pH}$ was achieved by the grapes of the $\mathrm{W}$ canopy side. E-W orientation, and particularly the $\mathrm{N}$-facing side of the canopy, seems inappropriate for the variety and site in question, since it presented the lowest phenolic levels in both grapes and wines at harvest.

Since no defoliation $\times$ exposition interaction was detected for the most important quality parameters of grape and wine composition, it would be safe to conclude that in the conditions of the studied area, the best way to ensure maximum anthocyanin accumulation in the skins and optimize wine polyphenolic composition would be to establish vineyards with N-S row orientation and practice bunch zone defoliation as early as berry set.

\section{References}

1. N.K. Dokoozlian, W.M. Kliewer. J. Am. Soc. Hortic. Sci., 121, 869- 874 (1996).

2. R.W. Emmett, A.R. Harris, R.H. Taylor, J.K. McGechan. Grape diseases and vineyard protection. Viticulture Vol. 2. Practices. Coombe BG, Dry PR (Eds). Winetitles, Adelaide pp 232-278 (1992).

3. R.Ristic, M.O. Downey, P.G. Iland, K. Bindon, I.L. Francis, M.J, Herderich, S.P. Robinson, Aust. J. Grape Wine Res., 13, 53- 65 (2007).
4. J. Bergqvist, N. Dokoozlian, N. Ebisuda, Am. J. Enol. Vitic., 52, 1- 7 (2001).

5. J.M. Tarara, J. Lee, S.E. Spayd, C.F. Scagel. Am. J. Enol. Vitic. 59:235-247 (2008).

6. I. Campos, C.M.U. Neale, A. Calera, Aust. J. Grape Wine R., 23, 77-86 (2017)

7. C. Intrieri, O. Silvestroni, B. Rebucci, S. Poni, I. Filippetti. In: Kling, T.H., Wolf, T.E., Harkness, E.M. (Eds.), Proc. 4th Intern. Cool Climate Symp., 16-20 July, Rochester, USA., pp. 10-15 (1996).

8. P. Iland, N. Bruer, G. Edwards, S. Weeks, E. Wilkes, Chemical analysis of grapes and wine: techniques and concepts (2004).

9. Compendium of International Methods of Analysis of Wines and Musts (2 vol.). Available from: http://www.oiv.int/en/technical-standardsanddocuments/methods-of-analysis/compendium-ofinternational-methodsof-analysis-of-wines-andmusts-2-vol.

10. P.G. Waterman, S. Mole S Analysis of phenolic plant metabolites, Oxford: Blackwell Scientific Publ pp 83-91 (1994).

11. P. Pieri, K. Zott, E. Gomès, G. Hilbert, OENO One, 50(3), 23-33 (2016).

12. M.O. Downey, J.S. Harvey, S.P. Robinson. Aust. J. Grape Wine Res. 10:55-73 (2004).

13. S. DeBolt, R. Ristic, P.G. Iland, C.M. Ford, Hort.Science, 43, 957-961 (2008). 